\title{
Winter Training Plan and Effect Analysis of Male Juvenile
}

Football Teams

\author{
Weiping Xie \\ Pingxiang University, Pingxiang, Jiangxi, 337055, China
}

Keywords: Youth football team; winter training preparation period

Abstract: By observing the actual training process during U-19 winter training, we can find out the problems in our training and find out what should be solved, and we can know the causes of these problems. We use sports training, pedagogy and psychology knowledge of these reasons, and put forward to solve these problems rationalization proposals. Provide reference for the coaches and relevant departments to effectively control training, improve training effectiveness, cultivate a high level of outstanding youth football reserve forces, and improve the overall level of football in China.

\section{Introduction}

Soccer training includes physical fitness, tactics, psychological and intellectual factors [1-3]. With the continuous improvement of sports level and science and technology to sports training, a strong impetus to become increasingly obvious, scientific training has become a major trend in training. To achieve the best training effect, not only depends on the effective management and organization of the training, but also on the effective control of the training process. Therefore, it is necessary to involve the methods of cybernetics, systems theory and information theory into sports training $[4,5]$. The coaches obtain the feedback information of the athlete's real state through timely, objective and effective means of testing and evaluation. They compare and analyze the existent states of the athletes. The training plan can be adjusted according to the general rule of sports training, and the control of the training plan can be completed [6]. The athletes can successfully develop to the target state so as to improve the training level.

In this study, we try to observe the actual training process of U-19 during winter training, and find out the problems in our training seriously and put forward some reasonable suggestions to solve these problems. Through the statistical analysis of the U-19winter training team stages and weekly plan, the problems in the design of the winter training plan and the weekly plan were found and rationalization suggestions were given to guide and arrange the follow-up training.

\section{Research object and research method}

\subsection{Study subjects}

22 youth soccer teams (534 athletes and 64 coaches) which participated in the 2004 U-19 age bracket. 


\subsection{Research methods}

(1) Documentation:

Through the computer retrieval, widely read the relevant literature at home and abroad [7, 8]. But also read many books, such as "sports training", "modern football", "basic psychology", "action and psychological development", "sports psychology", "Sports physiology", "sports management". As well as domestic and foreign youth football training papers and dozens of articles provide me with a strong theoretical support and writing ideas.

(2) Spot observation and statistical method:

Through the field observation interview record to participate in the basic situation of winter training teams, the coaches turned over to the stage plan and weekly training program classified statistics.

(3) Mathematical statistics:

Use SPSS13.0 software package to deal with statistical data, the analysis results.

(4) Logic Analysis:

Combined with professional knowledge and other related disciplines of knowledge, statistical analysis of the statistical data, comparison, come to related conclusions.

\section{Results and discussion}

\subsection{Analysis on the Matching of Number of Coaches and Athletes in Football Team}

According to the "Outstanding Sports Team Working Regulations" "Coach Code" promulgated by the former National Sports Commission, those coaches in the sports team play a leading role. Its main responsibility is to be responsible for the athletes training, competition, ideological education and management work, and continuously improve the technical level of athletes. Coaches also teach ideological and political consciousness, training moral, intellectual and physical development of the red and the excellent sports talents. The training and competition observation, statistics and analysis of the overall level of athletes and teams make timely and objective evaluation, in order to facilitate better control training. Football coaches are the controllers, instructors and organizers of football training. Needless to say, to improve the quality of training, the level of sports technology to achieve a qualitative breakthrough can not do without coaches and athletes two factors. Then in terms of a football team, the number of coaches with the number of players and the ratio between the numbers of possible training team on the situation is good or bad play a crucial role. Because a person's ability and limited scope, a coach at any time take full account of the twenty or thirty athletes each person's actual training situation. So constant monitoring is unrealistic. A soccer team with a reasonable coach in addition to follow certain rules of conduct and specific requirements, the number of its equipment should be based on the objectives of the football team tasks, job placement, the nature of the work and the amount of coaches within the team co-ordination arrangements. 
Table 1. Co-ordination tables for coaches and athletes at different levels

\begin{tabular}{cccccc}
\hline \multicolumn{5}{c}{ The proportion of the number of coaches and athletes distribution } \\
\hline & National & Provincial & Competitive & Key amateur & Ordinary \\
team & teams & sports & school & amateur school \\
Ratio & $1: 4$ & $1: 5$ & $1: 8$ & $1: 10$ & $1: 12$ \\
\hline
\end{tabular}

\subsection{The development stage of the classification plan statistics}

The teaching and training plan is the basic requirement and important link of the teaching and training work. Training process is a step, and there are plans for the athletes physical, technical, tactical, psychological and intellectual training, and continuously improve the level of competition in an educational process. Training program is a pre-theoretical design of practical activities, but also scientific control of the training process. To achieve the purpose of the established training is one of the most basic text materials. Rigorous and careful training plan not only can make the training work in an orderly manner, but also the coach of theoretical thinking and objective practice of continuous role. Checking and summarizing the training is very good basis. Gradually deepen the understanding of football training, and accumulation of experience to improve the quality of effective tools.

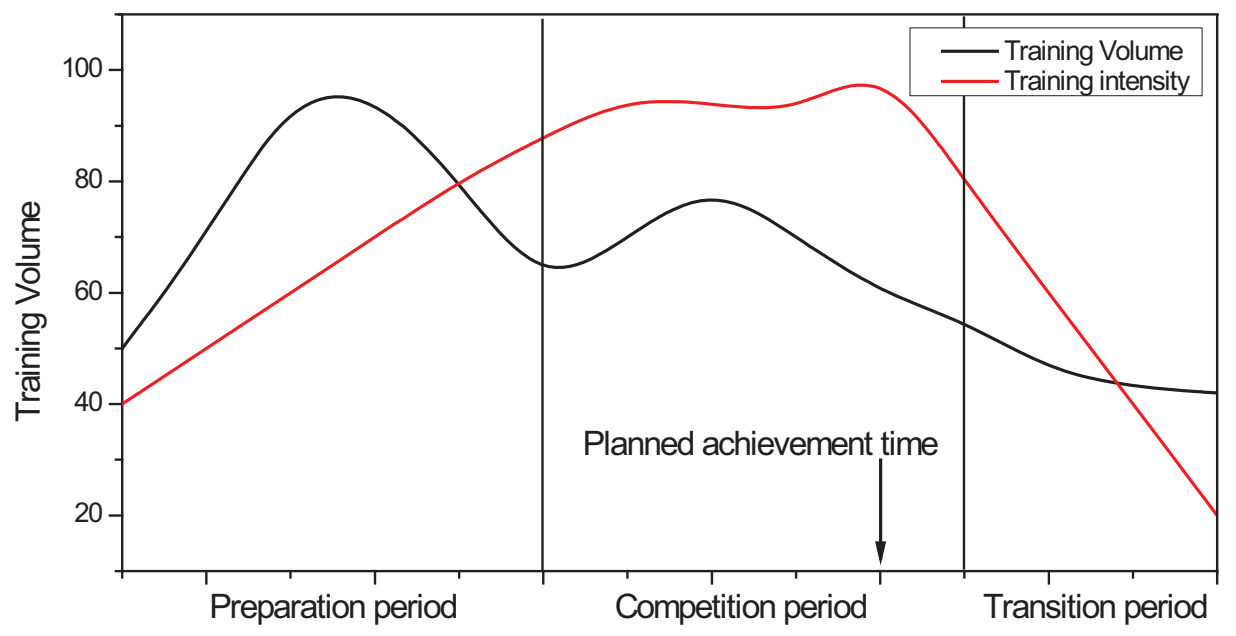

Figure 1. The basic model of the one-cycle training processof Matveev

\subsection{A statistical analysis of the actual training situation before participating in winter training}

To participate in the Chinese Football Association Winter Training, U-19 team transition period of preparation of the specific content of the statistical is drew the following table: 


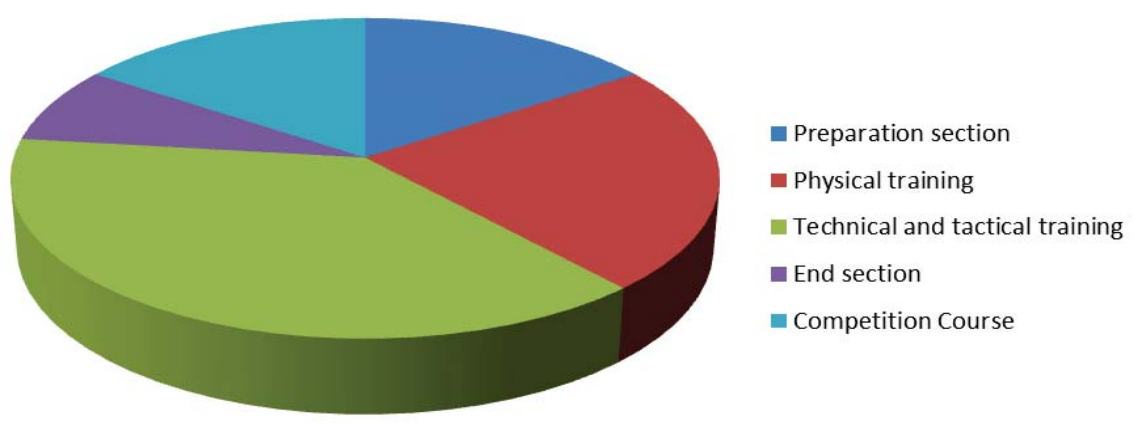

Figure 2. U-19 winter training team transition preparation period Specific details of the time scale diagram

Part of the preparation of 8020 minutes of the total time is $16.95 \%$. The basic part of the body training content is 4700 minutes of the total amount of time to participate in the training of Chinese Football Association U-19 winter training. Time is $19.43 \%$ of the total time. The content time of the technical and tactical training is 19,400 minutes, and is $41 \%$ of the total time. The content of the end part is 4160 minutes, $8.79 \%$ of the total time. Min of the total time is $23.20 \%$, and the total training time is 47320 minutes.

Statistics on the technical and tactical training contents (time) of the transitional preparation of the different teams of the U-19 Winter Training before the Chinese Football Association. The results of SPSS13.0 are as follows:

Table 2. Analysis of variance tables

\begin{tabular}{cccccc}
\hline & $\begin{array}{c}\text { sum of } \\
\text { square }\end{array}$ & $\begin{array}{c}\text { Degree of } \\
\text { freedom }\end{array}$ & $\begin{array}{c}\text { Average sum } \\
\text { of squares }\end{array}$ & F test & $\begin{array}{c}\text { Significa } \\
\text { nce }\end{array}$ \\
\hline In group & 31765.23 & 2 & 15845.43 & 3.445 & 0.054 \\
Between groups & 84345.54 & 19 & 4540.395 & & \\
Total & 118234.23 & 21 & & & \\
\hline
\end{tabular}

From the data of variance analysis, we can see that the significance is $0.051>$ 0.05. It indicates that there is no significant difference in technical and tactical training content (time) between the groups. That is to say, there is no fundamental difference in the content (time) of technical and tactical training between teams in different states, advance training, normal training and holiday.

\section{Summary}

With the increasing proportion of coaches, the equipments of coaches increases gradually. The situation is more reasonable. The training plan should be designed according to the specific characteristics of athletic training at different stages and at different periods, so as to make it more scientific and meet the requirements of different stages of training. It can also make the training more pertinent and obtain the best effect of training. Strengthen the youth football team management and 
investment, and improve the basic ability of young football players, and dilute the coach's sense of achievement. Continue to strengthen the scientific and rational training of young football players, and effectively improve the overall level of our young football players.

\section{References}

1. Faude O, Schnittker R, Schultezurhausen R, et al. High intensity interval training vs. high-volume running training during pre-season conditioning in high-level youth football: a cross-over trial.[J]. Journal of Sports Sciences, 2013, 31(13):1441.

2. Zhang Y, Liang S Y, Dai X H. Research on the Strength Training of Female Hammer Athletes in Winter Preparation Period[J]. Journal of Beijing Sport University, 2012.

3. Stoica D, Barbu D. The influence of specific football training methods during the preparation period upon the physical and motor development of 17-18 year-old juniors[J]. Palestrica of the Third Millennium Civilization \& Sport, 2014.

4. Shamardin V N. MANAGEMENT OF THE HIGHLY QUALIFIED FOOTBALL TEAM PREPARATION DURING THE TRANSITION PERIOD OF THE YEAR CYCLE OF TRAINING[J]. Pedagogics, Psychology, Medical-Biological Problems of Physical Training and Sports, 2012, 3.

5. Vasilyeva M, Farbey V. Forming-up of the training process for the winter politlonists aged 9-10 years at the stage of the initial preparation of the first and second year of training[J]. 2013(98):21-25.

6. Gao B Q, Chen L, Dong P. Optimizing the Teaching Process of Snowfield Football and Training Winter Exercise Habits of University Students[J]. China Winter Sports, 2013.

7. Ozolina L. BODY HYDRATION DEGREE CHANGES DURING TRAINING IN FOOTBALL PLAYERS IN WINTER CONDITIONS[J]. 2013, 4(2).

8. Dion S, Aguet C. Young Football Players: Training Policies[M]// CAS and Football: Landmark Cases. T. M. C. Asser Press, 2012:263-272. 